(6) OPEN ACCESS

\title{
Identification of flavour additives in tobacco products to develop a flavour library
}

\author{
Erna JZ Krüsemann, Wouter F Visser, Johannes WJM Cremers, Jeroen LA Pennings, \\ Reinskje Talhout
}

- Additional material is published online only. To view please visit the journal online (http://dx.doi.org/10.1136/ tobaccocontrol-2016-052961)

National Institute for Public Health and the Environment (RIVM), Bilthoven, The Netherlands

Correspondence to Professor Reinskje Talhout, National Institute for Public Health and the Environment (RIVM), Antonie van Leeuwenhoeklaan 9, $3721 \mathrm{MA}$ Bilthoven, The Netherlands; reinskje.talhout@rivm.nl

Received 5 February 2016 Revised 16 December 2016 Accepted 24 December 2016 Published Online First 12 January 2019
Check for updates

To cite: Krüsemann EJZ, Visser WF, Cremers JWJM, et al. Tob Control 2018:27:105-111.

\section{ABSTRACT}

Objectives This study combines chemical analysis and flavour descriptions of flavour additives used in tobacco products, and provides a starting point to build an extensive library of flavour components, useful for product surveillance.

Methods Headspace gas chromatography-mass spectrometry (GC-MS) was used to compare 22 commercially available tobacco products (cigarettes and roll-your-own) expected to have a characterising flavour and 6 commercially available products not expected to have a characterising flavour with 5 reference products (natural tobacco leaves and research cigarettes containing no flavour additives). The flavour components naturally present in the reference products were excluded from components present in commercially available products containing flavour additives. A description of the remaining flavour additives was used for categorisation.

Results GC-MS measurements of the 33 tobacco products resulted in an overview of 186 chemical compounds. Of these, 144 were solely present in commercially available products. These 144 flavour additives were described using 62 different flavour descriptors extracted from flavour databases, which were categorised into eight groups largely based on the definition of characterising flavours from the European Tobacco Product Directive: fruit, spice, herb, alcohol, menthol, sweet, floral and miscellaneous.

Conclusions We developed a method to identify and describe flavour additives in tobacco products. Flavour additives consist of single flavour compounds or mixtures of multiple flavour compounds, and different combinations of flavour compounds can cause a certain flavour. A flavour library helps to detect flavour additives that are characteristic for a certain flavour, and thus can be useful for regulation of flavours in tobacco and related products.

\section{INTRODUCTION}

According to the WHO Framework Convention on Tobacco Control, tobacco attractiveness, toxicity and addictiveness are important factors in tobacco product regulation. ${ }^{1}$ Characterising flavours other than the one of tobacco, mostly accompanied by packages with colourful designs, contribute to product attractiveness. Flavoured tobacco products are especially attractive to youth and therefore widely considered 'starter' products. ${ }^{1}$

A literature study performed by Feirman and colleagues shows that flavoured tobacco use is related to young age and that consumers prefer flavoured tobacco products over unflavoured products. ${ }^{2}$ Furthermore, Kreslake and colleagues analysed data from tobacco industry documents, which show that tobacco companies use strategies to manipulate sensory characteristics of cigarettes, for instance the menthol content, to facilitate smoking initiation. ${ }^{3}$ According to them, this strategy has been most successful in attracting youth and young adult smokers.

Overall, tobacco products with a characterising flavour stimulate young people to initiate smoking and therefore contribute to an increased use of tobacco products. ${ }^{14}$

The new European Union Tobacco Product Directive (EU TPD) 2014/40/EU prohibits characterising flavours in cigarettes and roll-your-own tobacco products. ${ }^{5}$ The TPD describes a characterising flavour as a 'clearly noticeable smell or taste other than one of tobacco, resulting from an additive or a combination of additives, including, but not limited to, fruit, spice, herb, alcohol, candy, menthol or vanilla, which is noticeable before or during the consumption of the tobacco product'. Notice that flavour is described as smell or taste. In this paper, we will distinguish flavours from flavour components, which are the chemical compounds responsible for the overall flavour of the product. A flavour component can be present in natural tobacco, but can also be added to tobacco (flavour additives).

Recently, it was proposed to assess characterising flavours by using a combination of a trained expert panel that assesses flavours by smelling tobacco samples, and headspace gas chromatography-mass spectrometry (GC-MS). ${ }^{6}$ Headspace is based on heat-assisted diffusion of volatiles such as flavours to the gas phase. Subsequently, these flavours can be identified and analysed with gas chromatography-mass spectrometry (GC-MS). It was also recommended that based on the GC-MS method, a large flavour library should be established to obtain patterns in added flavour components (flavour additives). The current paper follows up on that suggestion. Together, they form a standardised method for assessing the flavour of a tobacco product, upon which regulation can be based. Chemical analysis is required to determine which flavour components are added to tobacco products and to be able to quantify these flavour components. Since chemical analysis does not provide information concerning human perception of flavours, for regulation purposes chemical analysis should be complemented with knowledge obtained from sensory analysis. 
In this study, an analytical method was used to identify flavour additives in tobacco products using headspace GC-MS. Since headspace GC-MS focuses on volatile compounds, this technique is highly suitable and commonly used in flavour research. It has previously been investigated for the analysis of tobacco products, for instance to measure the concentration of flavour-related components in flavoured Indian-made bidi cigarettes and to characterise different strawberry-flavoured tobacco products for their volatile additives. ${ }^{78}$

Using our headspace GC-MS method, several cigarette and roll-your-own (RYO) tobacco products that were expected to have a characterising flavour, such as apple, strawberry or mango, were analysed to build a list of flavour additives (a flavour library). We also included some commercial brands that contain flavour additives, but that are not expected to have a characterising flavour. For brevity, these products will be referred to as 'characterising-flavour products' and 'non-characterising flavour products', in the rest of this manuscript. To distinguish flavour additives from flavour components present in natural tobacco, reference products were analysed as well. The group of reference products consists of two types of products: natural tobacco leaves and research cigarettes containing no additives.

The commercially available Leffingwell flavour database containing over 4000 descriptions of flavouring materials and additives, ${ }^{9}$ and internet sources, such as the Good Scents Company, were used to obtain flavour descriptions of the flavour additives. Together, this information comprises a tobacco additives flavour library that helps to discover flavour additives that are characteristic for a certain flavour, and is thus useful for regulation purposes concerning characterising flavours in tobacco products. We analysed the different tobacco products in terms of the amount of flavour additives in a brand, and the flavour complexity based on the flavour descriptions and amount of different flavour categories.

\section{MATERIALS AND METHODS}

Table 1 shows the products that were studied, which for the largest part overlap with those used in the study by the HETOC Consortium. ${ }^{6}$ The upper 22 products were selected based on the advertisements on packaging, the ingredient lists that tobacco manufacturers annually submit to the Dutch government, ${ }^{10}$ results from preliminary smelling experiments, information from employees in tobacco shops and information from the internet. Furthermore, six cigarettes from popular brands that are not expected to have a characterising flavour other than tobacco were investigated. All commercially available products were bought in (online) shops. Finally, the reference products consisted of five products which were known to contain no flavour additives: the 'Coresta Monitor 6' (CM6) cigarette (Borgwaldt, Hamburg, Germany), the 3R4F cigarette (University of Kentucky, USA) and three different types of tobacco leaves (Leaf Only, Middletown, Connecticut).

\section{Reagents and equipment}

Headspace GC-MS analysis was performed on an Agilent 7890B gas chromatograph equipped with an Agilent 5977 single-quadrupole mass spectrometer (Agilent Technologies, Amstelveen, the Netherlands) and a multipurpose sampler (MPS-2, Gerstel, Mühlheimander Ruhr, Germany). -Menthol, menthone and menthyl acetate were of analytical grade and purchased from Sigma-Aldrich (Zwijndrecht, the Netherlands).
Table 1 Tobacco products used for this study

\begin{tabular}{|c|c|c|c|c|}
\hline & No & Type & Brand & $\begin{array}{l}\text { Expected } \\
\text { flavour }\end{array}$ \\
\hline \multirow{22}{*}{$\begin{array}{l}\text { Expected characterising } \\
\text { flavour products }\end{array}$} & 1 & Roll-your-own & RYO-TP2 & Menthol \\
\hline & 2 & Cigarette & Cig-TP13 & Menthol \\
\hline & 3 & Cigarette & Cig-TP2 & Menthol \\
\hline & 4 & Cigarette & Cig-TP1 & Menthol \\
\hline & 5 & Cigarette & Cig-TP14 & Menthol \\
\hline & 6 & Cigarette & Cig-TP15 & Menthol \\
\hline & 7 & Cigarette & Cig-TP5 & Cherry \\
\hline & 8 & Cigarette & Cig-TP16 & Vanilla \\
\hline & 9 & Roll-your-own & RYO-TP3 & Vanilla \\
\hline & 10 & Roll-your-own & RYO-TP1 & Vanilla \\
\hline & 11 & Cigarette & Cig-TP4* & Vanilla \\
\hline & 12 & Cigarette & Cig-TP8* & Chocolate \\
\hline & 13 & Cigarette & Cig-TP7* & Unknown \\
\hline & 14 & Cigarette & Cig-TP9 & Apple \\
\hline & 15 & Cigarette & Cig-TP12 & Strawberry \\
\hline & 16 & Cigarette & Cig-TP10 & Honey \\
\hline & 17 & Cigarette & Cig-TP11 & Mango \\
\hline & 18 & Cigarette & Cig-TP17 & Mango \\
\hline & 19 & Cigarette & Cig-TP18 & Pina Colada \\
\hline & 20 & Cigarette & Cig-TP19 & Mojito \\
\hline & 21 & Cigarette & Cig-TP6* & Chocolate \\
\hline & 22 & Cigarette & Cig-TP3* & Chocolate \\
\hline \multirow{6}{*}{$\begin{array}{l}\text { Expected non- } \\
\text { characterising flavour } \\
\text { products }\end{array}$} & 23 & Cigarette & Cig-RP1 & Tobacco \\
\hline & 24 & Cigarette & Cig-RP2 & Tobacco \\
\hline & 25 & Cigarette & Cig-RP3 & Tobacco \\
\hline & 26 & Cigarette & Cig-RP4 & Tobacco \\
\hline & 27 & Cigarette & Cig-RP5 & Tobacco \\
\hline & 28 & Cigarette & Cig-RP6 & Tobacco \\
\hline \multirow[t]{5}{*}{ Reference products } & 29 & Cigarette & $\begin{array}{l}\text { Coresta Monitor } \\
6 \text { (CM6) }\end{array}$ & - \\
\hline & 30 & Cigarette & $\begin{array}{l}\text { University of } \\
\text { Kentucky (3R4F) }\end{array}$ & - \\
\hline & 31 & Leaves & $\begin{array}{l}\text { American } \\
\text { Virginia flue } \\
\text { cured } 2013\end{array}$ & - \\
\hline & 32 & Leaves & Un-cut Burley & - \\
\hline & 33 & Leaves & $\begin{array}{l}\text { Semi-Oriental } \\
456\end{array}$ & - \\
\hline
\end{tabular}

*The flavour of these products could not be inferred from the product packages. These products were included based on information from employees in tobacco shops and the internet (Cig-TP4 and Cig-TP8, the colourful design of the package (Cig-TP7), or ingredient lists that manufacturers annually send to the National Institute for Public Health and the Environment (RIVM) ${ }^{10}$ (Cig-TP6 and Cig-TP3).

\section{Sample preparation}

Tobacco of each product from a recently purchased and freshly opened package was pulverised using a mortar and pestle. Tobacco leaves were cut using a tobacco mill. Approximately 200 (194.0-218.6) mg tobacco of each product was used. For Cig-TP14, the capsule in the filter was squeezed to release menthol flavour. The filter and the tobacco were incubated for 24 hours to allow the menthol flavour to be attached to the tobacco. All tobacco samples were measured in triplicate. Between tobacco samples, two blank samples were measured to avoid carryover.

\section{Headspace GC-MS parameters}

The tobacco samples were incubated for $30 \mathrm{~min}$ in an agitator oven at a temperature of $140^{\circ} \mathrm{C}$. Preliminary tests indicated 
this was an optimal balance between sensitivity and excessive tobacco charring. Subsequently, a volume of $1 \mathrm{~mL}$ of the formed vapour was injected on the $\mathrm{GC}$ column. The syringe temperature was $130^{\circ} \mathrm{C}$.

An HP-5ms Ultra Inert capillary column $(30 \mathrm{~m} \times 0.25 \mathrm{~mm}$ $\times 0.25 \mu \mathrm{m}$ ) from Agilent Technologies was used for chromatographic separation. The GC conditions were as follows: injection mode, split; split ratio, 1:100 or 1:20; split flow, respectively 150 $\mathrm{mL} / \mathrm{min}$ or $30 \mathrm{~mL} / \mathrm{min}$. The $\mathrm{GC}$ oven temperature programme was as follows: initial, $50^{\circ} \mathrm{C}$; gradient, $10^{\circ} \mathrm{C} / \mathrm{s}$; end, $200^{\circ} \mathrm{C}$; hold time, $5.0 \mathrm{~min}$. Total run time is $20 \mathrm{~min}$. Helium was used as carrier gas at a constant flow of $1.5 \mathrm{~mL} / \mathrm{min}$. The injection temperature was $250^{\circ} \mathrm{C}$.

The MS settings were as follows: acquisition mode, full scan $\left(m / z\right.$ 40-500); transfer line, $280^{\circ} \mathrm{C}$; ionisation mode, EI; ionisation voltage, $70 \mathrm{eV}$; ion source, $230^{\circ} \mathrm{C}$; quadrupole, $150^{\circ} \mathrm{C}$; solvent delay, $3 \mathrm{~min}$; data acquisition rate, $3.2 \mathrm{scans} / \mathrm{s}$. Chromatograms were processed with GC-MS MassHunter Workstation software (Agilent Technologies).

\section{Identification of components}

A report of the components measured was generated using the Automated Mass Spectral Deconvolution and Identification System (AMDIS) software. ${ }^{11}$ This software identifies components based on the probability given by the Flavors and Fragrances of Natural and Synthetic Compounds Version 2 (FFNSC 2) database ${ }^{12}$ and the National Institute of Standards and Technology (NIST)/Environmental Protection Agency (EPA)/ National Institutes of Health (NIH) Mass Spectral Library with Search Program (NIST). ${ }^{11}$ Components with a peak-to-peak signal-to-noise ratio below 3 were discarded (corresponding to a signal-to-noise ratio'SNR' of approximately 55 as indicated by the AMDIS software). 'Weighted' and 'reverse' scores are AMDIS software-specific values associated with the probability of correct identification. Components with a 'weighted' and/ or 'reverse' score below 70\% were excluded. Components that were not observed in all three replicates were discarded.

The identification of menthol, isomenthone, menthone and menthyl acetate was confirmed using reference standards.

Components eluting more than $0.2 \mathrm{~min}$ apart were assumed to be different compounds, even if they could not be distinguished on the basis of their mass spectrum.

\section{Data processing: identification, categorisation and scoring of flavour additives}

From the list of identified components, five components present in large amount were excluded because they are well known to be no flavour additives: 1,2-propanediol; 1,3-propanediol, glycerol 1,2-diacetate; diethyl phthalate; and nicotine. All other compounds were considered possible flavour components.

The components naturally present in the reference products were excluded from components present in commercially available products containing flavour additives. The remaining flavour components were considered flavour additives, and a description of the remaining flavour additives was used for categorisation.

Flavour descriptions from the Leffingwell database, ${ }^{9}$ and other sources were used to score tobacco products as follows (an example of this calculation is shown in table 3). First, for each product, for each flavour additive in the database, a score was assigned based on its flavour description, with a total score of 1 . Flavour additives for which the description was unknown received a score of 0 .
Second, these flavour descriptions were categorised in eight different flavour categories: fruity, floral, alcohol, spicy, herbal, sweet, menthol and miscellaneous (table 3). The categorisation of flavour descriptors was largely based on the definition of characterising flavours in the TPD: 'clearly noticeable smell or taste other than one of tobacco, including, but not limited to, fruit, spice, herb, alcohol, candy, menthol or vanilla'. Vanilla and candy were combined in the category sweet and categories of floral and miscellaneous descriptors were added. Descriptors were categorised as miscellaneous when they were not described as either fruit, spice, herb, alcohol, menthol, sweet or floral.

Third, for each tobacco product, the sum of the flavour description scores was calculated for each category. This sum was expressed as the percentage of the total absolute score (figure 2).

\section{Statistical analysis}

The 33 products expected to be characterising flavour products, non-characterising flavour products and reference products were compared based on their chemical composition with a principal component analysis (PCA) using the statistical program ' $\mathrm{R}$ '. The PCA was centred on the average product.

\section{RESULTS}

\section{Chemical analysis}

As an example, figure 1 shows the chromatograms of Cig-TP5 tobacco, Cig-TP1 tobacco and Burley tobacco leaves. A complete overview of the components identified in the 33 cigarette and roll-your-own tobacco products is shown in online supplementary appendix 1 (supplementary data). This overview contains 186 chemical compounds. Of these, five were excluded since they do not impart a flavour as mentioned above; 37 other components were present in at least one of the reference products. It is well known that many components that are added to tobacco are also present in natural tobacco. ${ }^{13}$ Since the SNR can be compared between different products, and are in the same range for commercially available products and reference products, the amounts in both types of products are rather similar. The remaining 144 components were exclusively present in the commercially available characterising flavour and non-characterising flavour products, and hence were considered flavour additives. These 144 flavour additives were chemically identified using the FFNSC 2 and NIST mass spectral library.

\section{Categorisation of flavour additives}

A flavour description for 92 of the 144 flavour additives (online supplementary appendix 1) was found in the Leffingwell flavour database ${ }^{9}$; a description of 30 other components was found on the internet, for instance, on the website of The Good Scents Company; no flavour description of the remaining 22 components could be found. In total, 62 different flavour descriptors were identified. These flavour descriptions were categorised into eight groups, as summarised in table 2 .

A score associated with the presence of known flavour additives (ie, additives with a known flavour description) in each of the eight flavour categories was allocated to the commercially available tobacco products. An example of this calculation is given in table 3 .

The presence of a particular flavour category as percentage of the total absolute score is represented by the eight different colours in figure 2 .

The sum of the flavour additive scores for each tobacco product, equal to the total score, represents the number of known flavour additives in that particular product. This score might be useful to discriminate between characterising flavour and non-characterising flavour products: 19 out of 22 characterising 


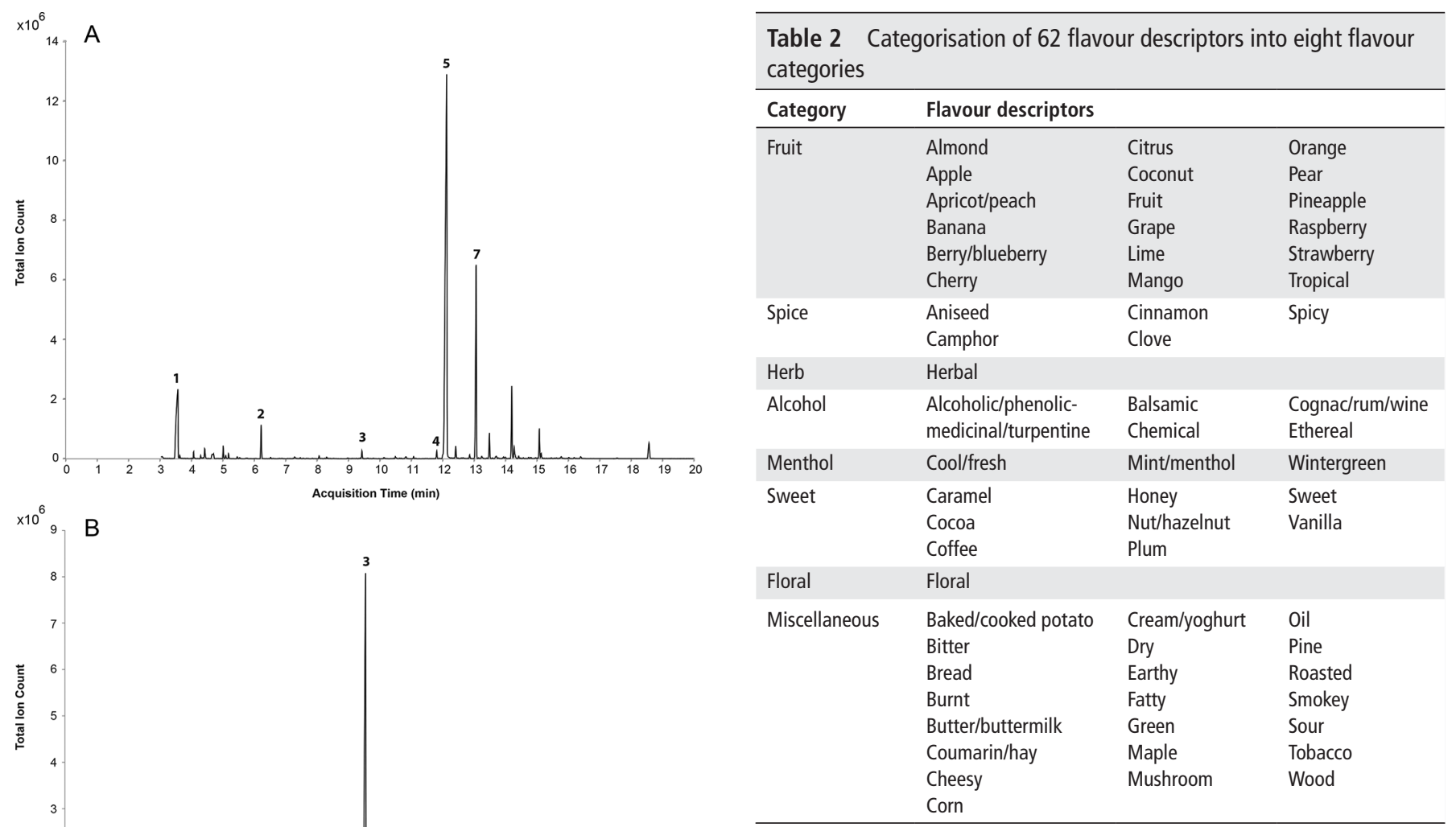

flavour additives used in cigarette and roll-your-own tobacco products, and online supplementary appendix 1 provides a starting point to build an extensive library of flavour components used in tobacco products. It contains the GC-MS retention time of flavour components, and a description of their perceived flavour, and can be used to determine which added flavour components cause the presence of a noticeable flavour in tobacco products. We have analysed several tobacco products that were expected to impart a characterising flavour, such as apple, strawberry, vanilla or mango. An extensive online flavour library should contain a complete overview of flavour additives present in all tobacco products, including products with a different flavour than those analysed in this paper and other tobacco products than cigarettes and roll-your-own products.

The flavour library helps to detect flavour additives that are characteristic for a certain flavour, and is thus useful for product surveillance of flavours in tobacco products.

\section{Chemical analysis}

In the future, the identification of flavour components should be confirmed using analytical standards, because absolute certainty regarding the identity of components is necessary for regulatory purposes. Similarly, their amount is of importance, in order to be able to determine whether the component is present in sufficient amounts to be perceived by consumers (for this, the human detection threshold must be known). The method described in this paper is qualitative, but because a wide range of flavour components were detected and chromatographically well resolved, it appears likely that headspace GC-MS could be used in the future to develop a quantitative method for flavour components in tobacco.

\section{DISCUSSION}

Products with strong non-tobacco flavours are popular among young people, and may facilitate smoking initiation. The current paper describes a procedure to identify the presence of 
Table 3 Example of deriving flavour description category scores for Cig-TP1 (cigarette), with a total score of 1 for each flavour additive

\begin{tabular}{|c|c|c|c|c|c|c|c|c|c|}
\hline Flavour additive & Flavour description* & Fruity & Floral & Alcohol & Spicy & Herbal & Sweet & Menthol & Misc \\
\hline 1,2-propanediol, 1-acetate & Unknown & 0 & 0 & 0 & 0 & 0 & 0 & 0 & 0 \\
\hline Menthol & $\begin{array}{l}\text { Cooling; less cooling than (-)-menthol, } \\
\text { with musty-minty notes }\end{array}$ & & & & & & & $\begin{array}{l}1 / 2 \text { (menthol)+1/2 } \\
\text { (minty) }\end{array}$ & \\
\hline 4-cyclopentene-1,3-dione & Unknown & 0 & 0 & 0 & 0 & 0 & 0 & 0 & 0 \\
\hline Menthone & $\begin{array}{l}\text { Minty-herbaceous (not green); dry } \\
\text { woody notes }\end{array}$ & & & & & $\begin{array}{l}1 / 4 \\
\text { (herbaceous) }\end{array}$ & & $1 / 4$ (mint) & $\begin{array}{l}1 / 4(\text { wood) }+1 / 4 \\
\text { (dry) }\end{array}$ \\
\hline Neomenthyl acetate & $\begin{array}{l}\text { Fresh, minty, slightly fruity for } \\
\text { (+)-neomenthyl acetate }\end{array}$ & $\begin{array}{l}1 / 3 \\
\text { (fruity) }\end{array}$ & & & & & & $\begin{array}{l}1 / 3 \text { (fresh) }+1 / 3 \\
\text { (minty) }\end{array}$ & \\
\hline Menthyl acetate & $\begin{array}{l}\text { Has a minty type odour and a cooling } \\
\text { type flavour }\end{array}$ & & & & & & & $\begin{array}{l}1 / 2 \text { (minty) }+1 / 2 \\
\text { (cooling) }\end{array}$ & \\
\hline $\begin{array}{l}\text { 1, 1,5-trimethyl-1, } \\
\text { 2-dihydronaphthalene }\end{array}$ & Unknown & 0 & 0 & 0 & 0 & 0 & 0 & 0 & 0 \\
\hline 1-hexanol, 2-ethyl- & $\begin{array}{l}\text { Sweet, oily fermenty weak rose odour; } \\
\text { fatty fruity-musty, tea-floral taste }\end{array}$ & $\begin{array}{l}1 / 5 \\
\text { (fruity) }\end{array}$ & $\begin{array}{l}1 / 5 \\
\text { (floral) }\end{array}$ & & & & $\begin{array}{l}1 / 5 \\
\text { (sweet) }\end{array}$ & & $\begin{array}{l}1 / 5 \text { (oily) }+1 / 5 \\
\text { (fatty) }\end{array}$ \\
\hline $\begin{array}{l}\text { 1H-pyrrole-2- } \\
\text { carboxaldehyde, 1-methyl- }\end{array}$ & Somewhat burnt, roasted, cracker, nut & & & & & & $1 / 3$ (nut) & & $\begin{array}{l}1 / 3 \text { (burnt) }+1 / 3 \\
\text { (roasted) }\end{array}$ \\
\hline Sum & & 0.53 & 0.20 & 0 & 0 & 0.25 & 0.53 & 2.92 & 1.57 \\
\hline$\%$ of total score & & 9 & 3 & 0 & 0 & 4 & 9 & 49 & 26 \\
\hline
\end{tabular}

*The flavour descriptions have been extracted from the Leffingwell flavour database ${ }^{9}$ or found on the internet such as the website of The Good Scents Company.

\section{Scoring and categorisation of flavour additives}

As shown in figure 2, the six commercially available non-characterising flavour tobacco products received a score of 3 or less. In contrast, 19 out of 22 products that were expected to possess a characterising flavour received a score $>3$. This suggests that the scoring system described can be a useful indicator to distinguish between characterising flavour and non-characterising flavour tobacco products. From the products initially expected to be flavoured, there were three products with a score $<3$ : Cig-TP7, Cig-TP6 and Cig-TP3. These products only contain one or two flavour additives, mostly associated with the miscellaneous flavours. Interestingly, the HETOC Consortium showed with sensory panel experiments that the odour of these products did not significantly differ from baseline products. ${ }^{6}$ Cig-TP6 contains only one menthol-like component. The concentration of this menthol-like component is low; the SNR is 60 (online supplementary appendix 1), which is comparable to the amount of menthol measured in non-characterising flavour products, (SNRs of the same menthol-like component in Cig-RP5 and Cig-RP6 are, respectively, 63 and 62). It needs to be noted that these products were not selected based on a flavour description from the product packages, but included based on the colourful design of the package (Cig-TP7), or ingredient lists that manufacturers annually send to the National Institute for Public Health and the Environment (RIVM) ${ }^{10}$ (Cig-TP6 and Cig-TP3, with slightly higher than usual amounts of flavour additives).

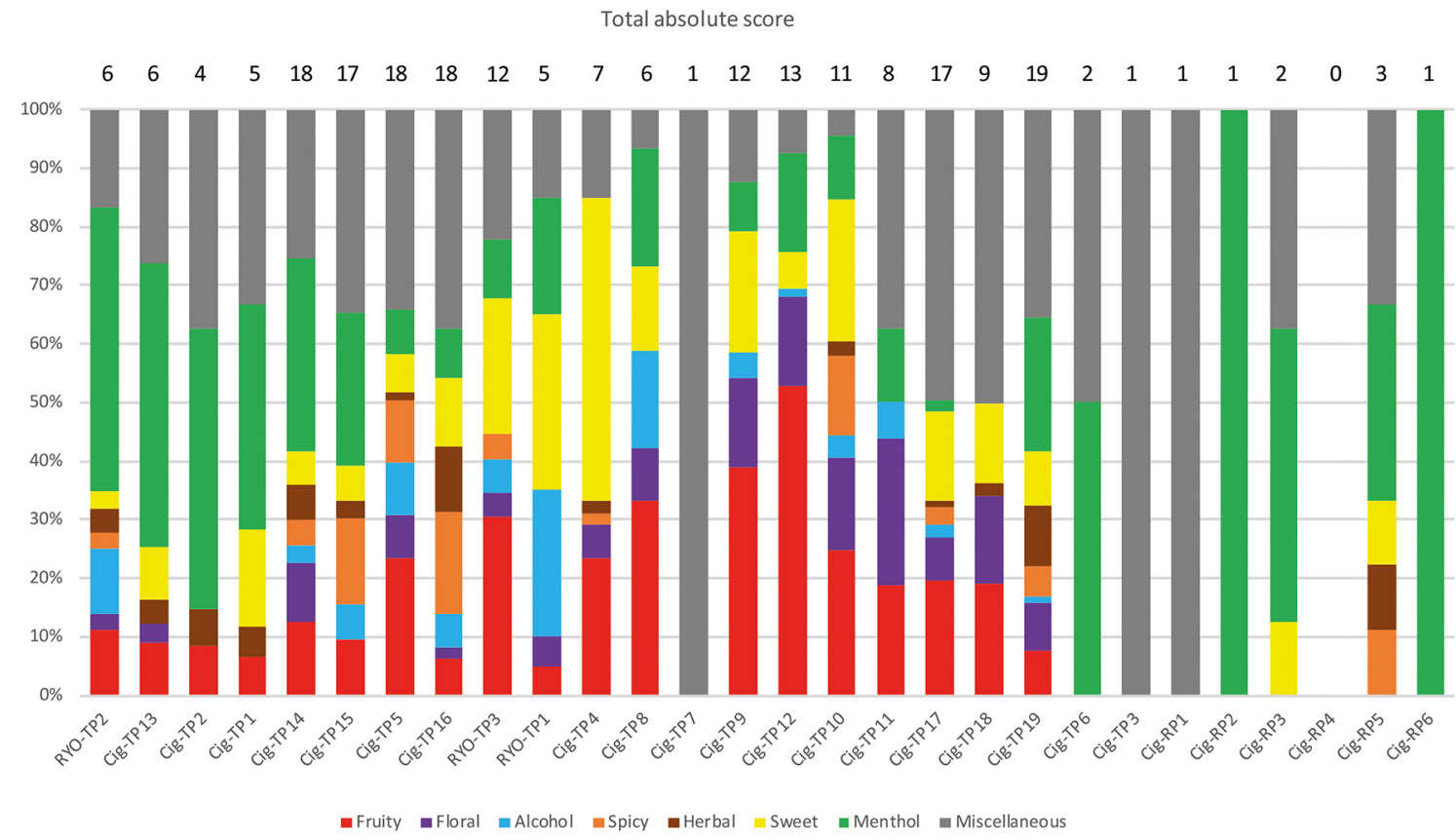

Figure 2 Flavour additives in tobacco products. Total absolute score per product is shown above the bars and represents the number of flavour additives. The colours represent the eight different flavour categories. The size of each coloured segment indicates the percentage of the total absolute score. The six bars on the right hand side represent commercially available non-characterising flavour tobacco products. 
Our categorisation of flavour descriptors (table 2) was largely based on the definition of characterising flavours in the TPD, and is in agreement with the categorisation used by Viola and colleagues for flavoured cigars. ${ }^{14}$ In general, there is a correlation between the most dominant flavour category present in the product and the brand name of the product, except for Cig-TP8 that scores highest on 'fruity'. It is striking that of the three products that were expected to have a characterising flavour but received a low score, two were expected to have a chocolate flavour.

Possibly, the flavour components associated with chocolate flavour are not readily detected using headspace GC-MS, or some of the components with an unknown flavour may actually impart a chocolate flavour. More chocolate-flavoured cigarettes should be tested to draw solid conclusions concerning this flavour.

\section{Complexity of flavours}

Vanilla and menthol consist of a single flavour compound instead of a complex mixture of flavour compounds, ${ }^{8}$ explaining the low score for many of the vanilla-flavoured and menthol-flavoured products. However, some of these products show more variation. Two products, RYO-TP1 and Cig-TP4, suggest that vanilla is a simple flavour, due to the low absolute score and the dominance of the sweet category. However, the other two products, Cig-TP16 and RYO-TP3, have a high absolute score and contain flavour additives belonging to multiple different categories, because these products consist of a complex mixture of flavour additives. For Kretek cigarettes, this can be explained by the presence of eugenol-like components in the flavour mix, responsible for the brand's characteristic clove flavour.

Furthermore, Cig-TP14 and Cig-TP15 are different from the other menthol-flavoured products, since their high score suggests that their flavours consist of a complex mixture of flavour compounds. Again, in case of the Kretek cigarette, this can be explained by the eugenol-like components contributing to its characteristic clove flavour.

Fruity flavours consist of a complex mixture with a large number of different flavour compounds. ${ }^{8}{ }^{15}$ For example, strawberry flavour contains approximately 360 different constituents. ${ }^{8}$ In addition, these products also contain flavour additives that belong to other categories. As a result, they are readily distinguished from non-characterising flavour products by the described scoring method.

Flavours are complex due to the fact that they consist of complex mixtures of multiple flavour compounds. In addition, a defined universal combination of flavour components that causes a certain flavour does not exist. Two products with similar perceived flavours may contain different combinations of flavour components. For instance, our chemical analysis has shown that two different mango-flavoured cigarette brands also have a different chemical composition (see online supplementary appendix 1). Furthermore, many flavour components are chiral molecules, that is, they are present in two different spatial forms that are mirror images of each other that cannot be superimposed, but are otherwise chemically identical. However, the two mirror images (enantiomers) often have quite different biological properties, such as their perceived flavour. Therefore, an analytical method aimed at predicting the flavour of a mixture as perceived by humans must be able to discriminate enantiomers, for example, by using chiral columns. ${ }^{8}$
Relation between chemical composition and perceived flavour

For regulatory purposes, it would be very useful if an estimate could be made of the expected flavour intensity of a tobacco product based on its chemical composition. However, flavour components have different odour thresholds. For instance, the odour thresholds of vanillin and ethyl-vanillin are respectively, 58 and 100, while the odour threshold of menthol is $400 .{ }^{9}$ Hence, higher amounts of menthol are required to obtain a similar odour intensity as with vanillin or ethyl-vanillin.

However, the available data on detection thresholds of pure flavour components is currently very limited, ${ }^{16-18}$ and because the matrix (ie, tobacco) may alter the detection threshold, it would be useful to establish detection thresholds of relevant flavour components in tobacco products. Based on human detection thresholds, maximum levels for certain flavour additives could be established for regulatory purposes. ${ }^{19} 20$

\section{Concluding remarks}

Based on our findings, we expect that an extensive flavour library will be a useful tool to identify tobacco products that may have a characterising flavour. As such, it will be helpful in jurisdictions where cigarettes and roll-your-own products with characterising flavours are regulated, for example, the European Union (TPD) and the USA (Tobacco Control Act, Sec. 907). It would also help to identify the flavour additives that are most frequently present and which, therefore, are of particular interest to regulators and health researchers. Brazil (RDC ANVISA No. 14) and Canada (BILL C-32) banned most flavours altogether.

Future research should focus on the development of quantitative methods for the analysis of flavour components in tobacco, and on establishing odour thresholds for flavour components in a tobacco matrix. Also, it would be helpful to perform further research into the flavour description of the components with an unknown flavour using sensory description experiments.

Because new tobacco products will continue to appear on the market, and manufacturers of tobacco products are likely to find solutions to evade detection and regulation of characterising flavour products, it will remain necessary to continuously update the flavour library and investigate additives used and their effects.

Apart from cigarette and RYO tobacco, our method can also be applied to test the presence of flavours in other traditional or new tobacco products such as flavoured cigars, the liquids that are vaporised in e-cigarettes, ${ }^{21}$ or the heat not burn products that recently appeared on the market like Philip Morris iQos. As

What this paper adds

- Flavours increase the appeal of tobacco products. Cigarettes with strong non-tobacco flavours are popular among young people, and may facilitate smoking initiation.

- The different types of flavour additives in cigarettes, and the complexity of their flavour description is not well characterised yet. Neither are the differences between products expected to have a characterising flavour, and those not expected to have such a flavour.

- A method is described to identify flavour additives in tobacco products, together with their flavour descriptions. Identifying flavours in tobacco and the resulting flavour library is important for regulatory purposes, for instance, to set upper limits to the levels of important flavour additives. 
such, it could be a helpful tool to determine whether the prohibition of characterising flavours should be extended to other products than cigarettes and roll-your-own tobacco.

Acknowledgements The authors thank Suzanne van de Nobelen for her assistance concerning the usage of the statistical program ' $R$ '. The authors also thank Ramon Ramlal for his technical help in the usage of chemical software, Eugène Jansen for his critical feedback on the manuscript and the HETOC study for contributing to the development and application of the methodology used in this paper. The HETOC study was funded under the EU Health Programme (2008-2013) in the frame of a service contract with the Consumers, Health, Agriculture and Food Executive Agency (Chafea) acting on behalf of the European Commission. The views expressed in the study are those of HETOC consortium and do not necessarily reflect the official opinion of the Executive Agency or the European Commission.

Contributors RT obtained study funding. RT, EJZK and JWJMC designed the study. EJZK and JWJMC carried out the experimental work. WFV, EJZK and JLAP conceived the scoring system. JLAP carried out the PCA. EJZK, RT and WFV drafted the manuscript.

Funding This study was supported by the Dutch Ministry of Health, Welfare and Sport, grant number V/050057.

Competing interests None declared.

Provenance and peer review Not commissioned; externally peer reviewed.

Open access This is an open access article distributed in accordance with the Creative Commons Attribution Non Commercial (CC BY-NC 4.0) license, which permits others to distribute, remix, adapt, build upon this work non-commercially, and license their derivative works on different terms, provided the original work is properly cited and the use is non-commercial. See: http://creativecommons.org/ licenses/by-nc/4.0/

(c) Article author(s) (or their employer(s) unless otherwise stated in the text of the article) 2018. All rights reserved. No commercial use is permitted unless otherwise expressly granted.

\section{REFERENCES}

1 World Health Organization. The Scientific Basis of Tobacco Product Regulation. Switzerland: World Health Organization, 2007:112.

2 Feirman SP, Lock D, Cohen JE, et al. Flavored tobacco products in the united States: A systematic review assessing use and attitudes. Nicotine Tob Res 2016;18:739-49.

3 Kreslake JM, Wayne GF, Alpert HR, et al. Tobacco industry control of menthol in cigarettes and targeting of adolescents and young adults. Am J Public Health 2008:98:1685-92.
4 Stanton CA, Villanti AC, Watson C, et al. Flavoured tobacco products in the USA: synthesis of recent multidiscipline studies with implications for advancing tobacco regulatory science. Tob Control 2016;25:ii1-ii3.

5 European Union. Directive 2014/40/EU of the European Parliament. Official Journal of the European Union, 2014.

6 HETOC Consortium. Mapping of best practices and development of testing methods and procedures for identification of characterising flavours in tobacco products. 2016. http://eceuropaeu/health/tobacco/docs/hetoc_frep_enpdf

7 Stanfill SB, Calafat AM, Brown CR, et al. Concentrations of nine alkenylbenzenes, coumarin, piperonal and pulegone in Indian bidi cigarette tobacco. Food Chem Toxicol 2003:41:303-17.

8 Paschke M, Hutzler C, Henkler F, et al. Toward the stereochemical identification of prohibited characterizing flavors in tobacco products: the case of strawberry flavor. Arch Toxicol 2015;89:1241-55.

9 Leffingwell \& Associates. Flavor-Base 9 - Tobacco Version. 2012. http://www. leffingwell.com/products.htm

10 RIVM. Toevoegingen tabaksproducten - Producten verkrijgbaar in Nederland. 2013.

11 The NIST Mass Spectrometry Data Center. NIST Standard Reference Database 1A: NIST/EPA/NIH Mass Spectral Library with Search Program. Including a tool for GC/MS deconvolution:AMDIS version 2.72. Data Version: NIST 14. Software Version: $2.2 \mathrm{~g}$ Retrieved 2015-12-02, from http://www.nist.gov/srd/nist1a.cfm.

12 Mondello L. FFNSC 2 - Flavors and Fragrances of Natural and Synthetic Compounds Mass Spectral Database. Software. 2nd edn, 2011.

13 Rodgman A, Perfetti TA. Tobacco and/or tobacco smoke components used as tobacco ingredients. The Chemical Components ot Tobacco and Tobacco Smoke. Boca Raton: CRC Press, 2013:1221-301.

14 Viola AS, Giovenco DP, Miller Lo EJ, et al. A cigar by any other name would taste as sweet. Tob Control 2016:25:605-6.

15 Brown JE, Luo W, Isabelle LM, et al. Candy flavorings in tobacco. N Eng/ J Med 2014;370:2250-2

16 Czerny M, Christlbauer M, Christlbauer M, et al. Re-investigation on odour thresholds of key food aroma compounds and development of an aroma language based on odour qualities of defined aqueous odorant solutions. Eur Food Res Technol 2008;228:265-73.

17 Siegmund B, Pöllinger-Zierler B. Odor thresholds of microbially induced off-flavor compounds in apple juice. J Agric Food Chem 2006;54:5984-9.

18 Rychlik M, Schieberle P, Grosch W. Compilation of Odor Thresholds, Odor Qualities and Retention Indices of Key Food Odorants. München, Germany: Garching: Deutsche Forschungsanstalt für Lebensmittelchemie und Institut für Lebensmittelchemie der Technischen Universität München, 1998.

19 Krüsemann EJZ CJ, Visser WF, Punter P, et al. The sensory difference threshold of menthol odor in flavored tobacco determined by combining sensory and chemica analysis. Accepted for publication by Chemical Senses 2016.

20 Talhout $R$, van de Nobelen S, Kienhuis AS. An inventory of methods suitable to assess additive-induced characterising flavours of tobacco products. Drug Alcohol Depend 2016:161:9-14

21 Visser W, Geraets L, Klerx W, et al. The health risks of using e-cigarettes. 2015. http:// www.rivmnl/dsresource?objectid=rivmp:311880\&type=org\&disposition=inline 